\title{
Education for Disaster Risk Reduction (DRR): Linking Theory with Practice in Ghana's Basic Schools
}

\section{Priscilla T. Apronti ${ }^{1, \dagger, *}$, Saito Osamu ${ }^{1, \dagger}$, Kei Otsuki ${ }^{1,2, \dagger}$ and Gordana Kranjac-Berisavljevic ${ }^{3, \dagger}$}

1 United Nations University Institute for the Advanced Study of Sustainability (UNU-IAS), 53-70, Jingumae, 5-chrome, Shibuya, Tokyo 150-8925, Japan; E-Mails: saito@unu.edu (S.O.); K.Otsuki@uu.nl (K.O.)

2 Department of Human Geography and Planning, Utrecht University, Heidelberglaan 2, 3584 CS Utrecht, The Netherlands

3 University of Development Studies (UDS), P.O. BOX TL 1350 Tamale, Ghana; E-Mail: novagordanak@gmail.com

$\dagger$ These authors contributed equally to this work.

* Author to whom correspondence should be addressed; E-Mail: prisvanti@gmail.com; Tel.: +81-804-089-4989.

Academic Editor: Armin Lude

Received: 4 April 2015 / Accepted: 2 July 2015 / Published: 15 July 2015

\begin{abstract}
Current understanding of disaster risk reduction (DRR) concurs that, when provided the right education, children have the potential to reduce their own vulnerability and the vulnerability of others in their community. What, then, comprises the right education for DRR? Research has established the need for disaster education to address the causes and effects, prevention and response, and management and recovery from disaster events. The educational process must include diverse and practical techniques that reinforce disaster knowledge and builds a culture of safety and resilience amongst students. Drawing on syllabus content analysis and field research in two rural communities in semi-arid Northern Ghana, this study explored the presence and nature of DRR within the syllabi of the basic school system. By comparing the result of the content analysis with results from interviews and questionnaires completed by teachers and students, significant gaps were identified between the disaster pedagogy outlined in the syllabi (theory) and that which occurs in the classroom (practice). It was realized that while the theory outlines active and innovative techniques for teaching, learning, and evaluating DRR lessons, various challenges hinder the practical application of these techniques in the classroom. The study concludes that a lack
\end{abstract}


of teacher training and professional development, and inadequate teaching and learning materials, generally account for these results. A new and consolidated effort is required from all stakeholders to train teachers and to provide the appropriate learning materials to improve on the current DRR education.

Keywords: disaster risk reduction; education; culture of prevention; safety; resilience; vulnerability; syllabi; Ghana

\section{Introduction}

In an era of increased human modification of nature, communities across the world have become more and more vulnerable to various forms of hazards. These hazards, which are either natural, man-made, or a combination of both, oftentimes result in disasters which have economic, socio-cultural, environmental, and political implications. The United Nations International Strategy for Disaster Reduction (UNISDR) defines disasters as "serious disruption of the functioning of a community or society involving widespread human, material, economic or environmental losses and impacts, which exceeds the ability of the affected community or society to cope using its own resources" [1]. Contesting opinions exist to this definition; which neglects the causes and rather focuses on the consequences of disasters. Gaillard [2] and Kelman [3] assert that disasters are consequences of human activities. This implies that, disasters primarily emerge from the socio-cultural, economic, and political structures of societies and its normal functioning and not due to the existence of hazards.

The impacts of disasters differ among individuals and societies depending on the level of exposure, the level of vulnerability, and the capacity to reduce, adapt to, and recover from the potential negative consequences [4]. Statistics on past disasters from governments and international organizations indicate that women, children, the elderly, and the disabled are the most affected [5-7]. The high level of exposure of children to disasters has been attributed to their physical fragility, their need for emotional support, and their dependence on others for decision-making [5,6]. They are also open to emotional and psychological trauma and physical abuse during, and after, disasters events [8]. Between 1990 and 2000, approximately 77 million children were affected by natural hazards and conflicts globally, with this figure expected to increase to 175 million by the end of 2017 [5].

The above statements tend to victimize children and present them as passive victims, who can contribute very little to their safety and those of members of their communities as has been reflected in their exclusion from discussions and theories on risk communication [8-10]. However, contemporary research into disaster risk reduction has established that through effective education, children can be actively involved in identifying their own exposure and consequential level of risk to various disasters. They can also be empowered to identify, prevent certain disasters, and make decisions that reduce these risks [1,8,9,11-15]. Empirical studies by UNISDR [1], Mitchell et al. [8] and Izadkah and Hosseini [9] have shown that education develops a culture of preparedness and increases safety and resilience by creating awareness of disasters. Education also better enables an understanding of risks and options to reduce impact by providing practical steps for disaster prevention, management, and recovery. 
Despite these, education for disaster risk reduction (DRR) has been criticized for its potential to shift the burden of DRR from the government and DRR institutions to individuals and society [16]. Thus, governments and institutions have no motivation to address shortfalls in their DRR operations and systems. Although this study agree with this assertion and stresses that disaster education should not be viewed and used as a replacement for the formulation and implementation of institutional initiatives and responsibilities at DRR, it also recognizes that institutional and systems failure, as well as limited capacities of DRR institutions, makes disaster education an inevitable necessity. These failures and resource constraints are particularly evident in developing countries where DRR institutions depend massively on government budgets which are, oftentimes, inadequate. This has reduced the activities of DRR institutions to being merely reactive. It is therefore of much interest not only to governments and institutions, but also to individuals, that they are adequately equipped to undertake disaster prevention, management, and proper response activities which could be their only means of surviving a disaster. However, the content of disaster messages and the approaches in delivering DRR messages must be situated in context to prevent misunderstandings and ensure that they do not reinforce existing social divides between experts and locals [16]. International initiatives have been addressing the importance of education for DRR, as seen in the UN Decade for Education for Sustainable Development (2005-2014) and the third priority for action of the Hyogo Framework for Action (HFA) (2005) [17-20].

Ghana is faced with numerous disaster events, such as annual floods and droughts, health epidemics, fire outbreaks, earth tremors, and infestations from pests and parasites [21]. In 2013, 5489 fire outbreaks were recorded in the country, resulting in a total economic loss of US\$6,834,424 [22]. The impact of these disasters is exacerbated by weak early warning systems, slow response mechanisms, poorly planned infrastructure development, and high levels of poverty. In reaction to this and other prior devastating events, the Government of Ghana initiated various proactive and reactive measures to deal with disasters. One such initiative is the mainstreaming of DRR into the national education system. In doing so, the infusionist approach, rather than a dedicated subject approach, at mainstreaming DRR has been the focus. The infusionist approach allows for the integration of DRR into already existing subjects, unlike the dedicated subject approach, which involves the creation of a new subject solely devoted to the teaching of DRR. The infusionist approach does not require the development of a new syllabus, teaching and learning materials, or specialized training for teachers who will handle the subject [23] which serves as both a strength and weakness of this approach. By integrating DRR into the existing education system, it is expected that disaster risk awareness and relevant skills will be developed, leading to more effective DRR.

However, effective DRR education can only take place if critical attention is given to the scope and content of disaster themes and topics, as well as the teaching, learning, and evaluation techniques used in the classroom [19,24]. This would require the formulation of effective and practical disaster syllabi, alongside specialized training for those teachers who would be delivering DRR education [19,23,25].

Selby and Kagawa [23] outline six teaching and learning techniques, (as summarized in Table 1) which builds on students' existing knowledge and experience by developing additional competencies needed for effective disaster prevention, management, and response [19,23]. These techniques require more active participation from students, in contrast to a passive lecture technique. In theory, a passive learning approach limits the ability to which skills can be developed and attitudes changed toward disaster prevention, safety, and resilience building. 
Table 1. Teaching and learning techniques for DRR.

\begin{tabular}{ll}
\hline \multicolumn{1}{c}{ Techniques } & \multicolumn{1}{c}{ Description } \\
\hline Interactive & Engages students in brainstorming and discussion on a given topic \\
Surrogate experiential & Uses proxies of real life events e.g., film making, role play \\
Field experiential & Undertaking practical activities outside the classroom e.g., hazard mapping \\
Affective & Students share their feelings and experiences of disaster events \\
Inquiry & Obtaining information from outside the classroom e.g., internet enquiries \\
Action & Active involvement of students in practical sessions \\
\hline
\end{tabular}

Source: Selby and Kagawa, 2012 [23].

This paper proposes to explore how this theory has been unfolding in practice in Ghana with the focus on the basic school system. More specifically, this study was driven by two main objectives: (i) to assess the current state of disaster education and communication within basic schools in Ghana and (ii) to investigate the nature, form of, and hindrances to effective disaster (natural and man-made) knowledge transfer from teachers to students. To achieve these objectives, the study undertook detailed content analyses of the national level basic school course syllabi and administered structured questionnaires to students within two selected communities in the Northern Region of Ghana. Focus group discussions were held with teachers and key informant interviews were conducted with individual teachers and an officer with the Ghana Education Service. The Northern Region is a disaster-prone area of Ghana, with events such as floods, droughts, health epidemics, and fire outbreaks commonly affecting households and communities [26]. The region is also characterized by high poverty and illiteracy [26-28], and is vulnerable to climate and ecosystem changes. This makes the region highly pertinent to the present study.

\section{Materials and Methods}

\subsection{Study Area Information}

The Northern Region of Ghana forms part of the 10 administrative regions of the country and covers a total of 70,383 $\mathrm{km}^{2}$ (approx. 30.0\%) of Ghana's land area. The Northern Region together with the Upper West and Upper East Regions occupies about 41.0\% of Ghana's land area. These regions form Northern Ghana and are the poorest, with $54.0 \%$ of the $18.0 \%$ of Ghanaians living in extreme poverty residing there [27].

Rainfall and temperatures in the study area are irregular, intermittent and torrential. Temperature averages are around $25^{\circ} \mathrm{C}$ to $36^{\circ} \mathrm{C}$, with an average annual rainfall range of 900-1000 mm. [29-31]. Ecosystems that used to regulate and support the environment and people in times of extreme weather conditions have been exploited. Flood and drought have become annual and prolonged events, with occasional fire outbreaks and bush fires.

The field research for this study took place over the period of one month (August 2014) in the communities of Kpalgun $\left(9^{\circ} 28^{\prime} \mathrm{N}, 1^{\circ} 5^{\prime} \mathrm{W}\right)$ and Yoggu $\left(9^{\circ} 30^{\prime} \mathrm{N}, 1^{\circ} 4^{\prime} \mathrm{W}\right)$, located within the Tolon district of the Northern Region [32]. The two villages are located near each other, with similar physical and socioeconomic characteristics. Yoggu has an estimated population of 3751, and Kpalgun's is 1573. These communities are amongst the CECAR-Africa project communities selected for being prone to extreme weather events. Selection was based on a community resilience assessment model used to 
determine the levels of vulnerability and resilience of selected communities in various districts in northern Ghana. This model took into consideration various elements of ecological, engineering and socio-economic dimensions of the communities. From the assessment, two districts; Tolon (six communities) and Wa West (four communities) were selected for their high exposure and vulnerability to droughts and floods respectively [33]. The estimated total number of households in Kpalgun is 111, and 216 in Yoggu, and the predominant occupations are subsistence farming and animal rearing. Since the agricultural sector largely depends on rainfall, most of the inhabitants become seasonally under-employed during dry seasons.

\section{Basic School System in Ghana}

The basic school system in Ghana comprises primary school and junior high school (hereafter JHS). Primary education is divided into lower and upper primary. Lower primary constitutes the first three elementary grades of primary education, with the ages of students averaging 6-8 years. The upper primary consists of the elementary grades 4, 5, and 6, with 9-12 years being the average age for students. At both elementary levels, students are expected to study nine main subjects, namely English Language, Integrated Science, Citizenship Education, Creative Arts, Information and Communications Technology (ICT), Ghanaian Language and Culture (GL\&C), Religious and Moral Education (RME), Mathematics, and Physical Education (PE). Students then proceed to JHS, which is made up of three classes (JHS 1, 2 , and 3). The average age range of students at this level is 13-16 years. At the JHS level, students are required to study eleven (11) different subjects: Integrated Science, GL\&C, Social Studies, English Language, Mathematics, PE, RME, Music and Dance, Basic Design and Technology (BD\&T), French, and ICT. Students then progress onto either senior high school or a vocational/technical institute. As students move from elementary school to senior high and tertiary school, there is a corresponding decrease in student enrolments and attendance, especially amongst females [34].

This study focuses on the upper primary and JHS levels within the basic education system. Grotberg [35] posits that children under the ages of seven are at the very fundamental developmental stages and can barely separate fantasy from reality and lies from truth. However beyond age seven, children are actively engaged in mastering skills particularly in schoolwork and can complete tasks and work with others more efficiently. Thus, from upper primary, students can provide appropriate responses to questions asked and their attitudes and skills can be shaped to create a culture of prevention and safety amongst communities. Moreover, large numbers of children can be reached and influenced due to the free and compulsory basic education initiative of the Government of Ghana.

This study did not evaluate the syllabi of subjects studied beyond JHS and could not include lesson observation as a process of data collection. Nevertheless, since the average years of experience of the teachers interviewed was five years and the majority of student respondents (79\%) have been exposed to the syllabi and its implementation over a relatively lengthy period of time (between two to six years), the results of this study reflect the actual situation in the classrooms. The study also did not undertake textbook analysis to obtain in-depth information on DRR topics and themes, since a wide variety of textbooks are recommended by the government and used in various schools; thus, the syllabi is the only standard document that is used in all school in Ghana. 
National statistics on education show that the Northern Region has the highest illiteracy rates in the country. The 2010 Population and Housing Census revealed that the region has a $62.8 \%$ illiteracy rate among those of its population 11 years and older, and more than $56.0 \%$ of its population has never attended school [34]. Table 2 gives a brief profile of the study community schools.

Table 2. Profile of schools in the selected communities.

\begin{tabular}{|c|c|c|c|c|c|c|c|}
\hline \multirow{3}{*}{ Name of School } & \multirow{3}{*}{ Gender } & \multicolumn{3}{|c|}{ Kpalgun } & \multicolumn{3}{|c|}{ Yoggu } \\
\hline & & \multicolumn{3}{|c|}{ Kpalgun Primary \& JHS } & \multicolumn{3}{|c|}{ Yoggu D/A Primary \& JHS } \\
\hline & & Lower Primary & Upper Primary & JHS & Lower Primary & Upper Primary & JHS \\
\hline \multirow{2}{*}{ No. of students } & Male & 81 & 95 & 89 & 80 & 44 & 86 \\
\hline & female & 41 & 66 & 47 & 51 & 32 & 38 \\
\hline Total & & 122 & 161 & 136 & 131 & 76 & 124 \\
\hline \multirow{2}{*}{ No. of teachers } & Male & 4 & 3 & 10 & 3 & 3 & 8 \\
\hline & Female & - & - & - & - & - & 1 \\
\hline Total & & 4 & 3 & 10 & 3 & 3 & 9 \\
\hline
\end{tabular}

Note: JHS_Junior High School.

\subsection{Data Collection and Field Work}

\subsubsection{Questionnaires}

Questionnaires were prepared and administered to students in August, 2014 to obtain students' knowledge on, and reaction to, certain disaster events and the nature of disaster risk communication from teachers to students. The questionnaires were developed based on an extensive literature review [5,8,19,23,36,37] and were qualitative. Particularly, empirical work conducted by Mamogale [37] on "Assessing disaster preparedness of learners and educators in Soshanguve North", works by Selby and Kagawa [23] and the Children Charter: an action plan for disaster risk for children by children [38], influenced the development of the questionnaires for students. A random sampling technique was used to select the households from which students were surveyed. Using the sampling determination technique developed by Israel [39], 165 questionnaires (Kpalgun: 69, Yoggu: 96) were administered to students from the two communities, of which 144 students responded (Kpalgun: 67, Yoggu: 77). Thus, a 17.0\% non-response rate was recorded for Yoggu and 2.0\% for Kpalgun due to the unavailability of some students during the time of the survey. Equal numbers of males and females could not be reached during the period of survey (because of the low number of female students in schools or their temporary unavailability) leading to more male respondents than female. Thus in Kpalgun, 45 male and 22 female respondents, and in Yoggu, 56 male and 21 female respondents were surveyed.

\subsubsection{Focus Group Discussions and Key Informant Interviews}

An in-depth focus group discussion was held on the 17 August 2014, with 15 teachers from the study communities. Teachers were selected using the snowball sampling technique and were pre-informed of the date and time for the interview session. All participating teachers were males, as the only female teacher in the selected study schools who had earlier agreed to participate did not turn up on the day of the interview. The semi-structured interview guide questions were developed based on extensive 
literature review $[8,19,23,36,37]$ and preliminary survey conducted with 40 upper primary and JHS teachers in February, 2014. The discussions produced information on the DRR topics taught in the classroom as well as how teachers delivered and evaluate DRR lessons. This was to identify if any discrepancies existed between the syllabi-stipulated DRR lesson and DRR lessons that take place in the classroom. During the focus group discussion, relevant issues were identified for which further insights were needed. Key informant interviews were conducted with individual teachers to obtain information specific to their training and experience with teaching disaster topics and themes. It was also to ensure that teachers had the opportunity to include responses that might have been left out during the focus group discussion.

A set of preliminary survey interview guide questions was developed based on the objectives of the study and literature $[8,23,36]$. Following the outcome of the survey conducted in February, 2014, with an officer from the Curriculum and Research Development Division (CRDD) of the Ghana Education Service (GES), an elaborate semi-structured interview guide was developed and administered to the Deputy Director in charge of Planning (GES) at the Tolon District in August, 2014. This was to validate key information obtained and obtain further clarification on the efforts of the institution at revising the curricular and DRR lessons, training of teachers for effective DRR lesson delivery, and the challenges with DRR education.

\subsection{Data Analysis}

\subsubsection{Content Analysis Process}

The content analysis method was used to identify the scope and content of disaster themes and topics within the syllabi of basic schools in Ghana. Specifically, the manifest and latent content analyses techniques were used [40]. The main material used for the content analysis was the syllabi of the various subjects studied within the upper primary and JHS in Ghana. Tables 3 and 4 gives details of the upper primary and JHS syllabi used for the content analysis. This was obtained as an electronic version from an officer at the Ghana Education Service. A list of 24 words relevant to the disaster risk reduction discourse was identified and used for the syllabi analysis. The words were selected using the following three criteria:

(1) Core words within the DRR discourse, such as hazard, disaster, vulnerability, risk, and resilience, were obtained from literature and web-based resources from various institutions, such as United Nations International Strategy for Disaster Reduction (UNISDR terminologies) [41] and Department of Community Safety, State of Queensland [42].

(2) Five words found within the scope of the DRR, which are: cause, effects, prevention, recovery, and management of disasters which are found in UNISDR terminologies and other literature.

(3) Common disaster events in Ghana, particularly in the study communities. Examples include floods, droughts, windstorm, and fires. 
Table 3. Details of the subjects syllabi in the Upper Primary.

\begin{tabular}{|c|c|c|c|c|}
\hline No. & Upper Primary Subjects & Title of Syllabus & $\begin{array}{c}\text { Year of } \\
\text { Publication }\end{array}$ & $\begin{array}{l}\text { Total No. of } \\
\text { Pages }\end{array}$ \\
\hline 1 & Citizenship Education & Teaching syllabus for Citizenship Education (Primary 4-6) & September, 2007 & 44 \\
\hline 2 & Integrated Science & Teaching syllabus for Integrated Science (Primary 4-6) & September, 2012 & 35 \\
\hline 3 & English Language & Teaching syllabus for English Language (Primary 4-6) & September, 2012 & 80 \\
\hline 4 & Creative Arts & Teaching syllabus for Creative Arts (Primary 4-6) & September, 2007 & 93 \\
\hline 5 & $\begin{array}{l}\text { Information and Communications } \\
\text { Technology }\end{array}$ & $\begin{array}{l}\text { Teaching syllabus for Information and Communications Technology } \\
\text { (Primary 1-6) }\end{array}$ & September, 2007 & 37 \\
\hline 6 & Ghanaian Language and Culture & Teaching syllabus for Ghanaian Language and Culture (Primary 4-6) & September, 2012 & 93 \\
\hline 7 & Religious and Moral Education & Teaching syllabus for Religious and Moral Education (Primary 1-6) & September, 2008 & 76 \\
\hline 8 & Mathematics & Teaching syllabus for Mathematics (Primary 1-6) & September, 2012 & 160 \\
\hline 9 & Physical Education & Teaching syllabus for Physical Education (Primary 1-6) & September, 2007 & 91 \\
\hline
\end{tabular}

Table 4. Details of the subjects syllabi in the JHS.

\begin{tabular}{|c|c|c|c|c|}
\hline No. & Junior High School Subjects & Title of Syllabus & $\begin{array}{c}\text { Year of } \\
\text { publication }\end{array}$ & $\begin{array}{c}\text { Total No. of } \\
\text { Pages }\end{array}$ \\
\hline 1 & Integrated Science & Teaching syllabus for Integrated Science (JHS 1-3) & September, 2012 & 65 \\
\hline 2 & Social Studies & Teaching syllabus for Social Studies (JHS 1-3) & September, 2007 & 51 \\
\hline 3 & Music and Dance & Teaching syllabus for Music and Dance (JHS 1-3) & September, 2008 & 29 \\
\hline 4 & Building Design and Technology & Teaching syllabus for Building Design and Technology (JHS 1-3) & September, 2007 & 132 \\
\hline 5 & English Language & Teaching syllabus for English Language (JHS 1-3) & September, 2012 & 118 \\
\hline 6 & $\begin{array}{l}\text { Information and Communications } \\
\text { Technology }\end{array}$ & $\begin{array}{l}\text { Teaching syllabus for Information and Communications Technology } \\
\text { (JHS 1-3) }\end{array}$ & September, 2007 & 50 \\
\hline 7 & Religious and Moral Education & Teaching syllabus for Religious and Moral Education (JHS 1-3) & September, 2008 & 56 \\
\hline 8 & Mathematics & Teaching syllabus for Mathematics (JHS 1-3) & September, 2012 & 84 \\
\hline 9 & Physical Education & Teaching syllabus for Physical Education (JHS 1-3) & September, 2007 & 73 \\
\hline 10 & French & Teaching syllabus for French (JHS 1-3) & September, 2007 & 88 \\
\hline 11 & Ghanaian Language and Culture & Teaching syllabus for Ghanaian Language and Culture (JHS 1-3) & September, 2007 & 57 \\
\hline
\end{tabular}


After these words were selected, a list of words, with similar meanings to the selected 24 words, was identified. The identification of the synonym words or phrases was done in consultation with teachers based on their experience with the curriculum and words normally used in their lessons in the classroom. This was done because the authors recognized that the selected words could be represented in the syllabi with different words and phrases that have the same meaning. Synonyms for the words fire, climate change, and epidemics were not required. Table 5 shows the key words with their synonyms used in the content analysis.

Table 5. Disaster key words and their synonyms.

\begin{tabular}{clcl}
\hline Key Words & \multicolumn{1}{c}{ Synonyms } & Key Words & \multicolumn{1}{c}{ Synonyms } \\
\hline Hazard & Menace, threat & Recover(y) & Recuperate, get well \\
Disaster & Calamity, tragedy & Response & React, handle \\
Risk & Danger, exposure & Manage(ment) & Control, cope \\
Vulnerability & Prone to, predisposed to & Capacity & Ability, aptitude \\
Climate change & - & Flood & Inundation, overflow \\
Resilience & Overcome & Drought & Lack of water \\
Causes & Sources, reasons & Fire & - \\
Effects & Consequence, result of & Earthquake & Earth tremor, vibration in the earth \\
Prevent & Avoid, stop & Pests & Vermin, parasite \\
Protect & Safeguard, keep & Diseases & Ailment, infection \\
Safety & Secure, welfare & Epidemics & - \\
Adapt & Adjust, cope & Windstorm & Rainstorm, whirlwind \\
\hline
\end{tabular}

The analysis of the syllabi was limited to the above words (Table 5) and focused on the types of disasters, the scope and content of the disaster topics, i.e., the cause, effects, prevention, recovery, and management of disaster events. The teaching and learning activities outlined in the syllabi, as well as evaluation techniques, were also considered for this study.

Using the manifest content analysis process, we identified the presence of the words in the syllabi and the frequency with which they occurred. Thus, before the use of a word in the syllabi was included in this study, it had to have been used in a disaster-related context. By disaster-related context, it means the words were used in connection with a natural or man-made event with the potential for causing direct or indirect harm to a group of people, and requiring external assistance to address the problem. Concurrently, the sections of the syllabi in which the words were identified were coded sentence-by-sentence using latent content analysis process. This enabled the identification of the nature of disasters, their causes, effects, prevention and management. Also, the teaching, learning and evaluation techniques stipulated for disaster themes and topics in the syllabi as well as the extent to which students should be involved in DRR activities were identified and analyzed during this process. Results from the manifest syllabi analysis process are presented in the graphs below (Figures 1 and 2).

\subsubsection{Questionnaire and Interview Data Analysis}

The information obtained from the questionnaires administered to students and key informant interviews with individual teachers were coded and analyzed to generate frequencies and percentages which were used in the study. Thus, the information was classified into: 
(1) Scope and content of disaster themes and topics taught in the classroom

(2) Teaching, learning, and evaluation activities employed in the classroom

(3) Competencies developed and challenges faced through classroom DRR education

Results obtained from the questionnaires administered to students, key informant interviews with teachers, together with focus group discussion with teachers, were compared with the outcome of the content analysis to identify the coherence and discrepancies that exist. Through literature review [23], a list of DRR teaching, learning and evaluation techniques were identified and used in classifying the teaching and learning activities identified in the syllabi. Teachers were then asked to identify the techniques they employ in teaching DRR in the classroom. The responses of teachers were then classified under the same DRR teaching and learning techniques identified from the literature. This was then compared with the outcome of the syllabi content analysis. Interviews with an officer from the Ghana Education Service and focus group discussion with teachers from the district were used to support key findings.

\subsubsection{Strengths and Limitations of Research Approach}

The analysis of the upper primary and JHS subject syllabi based on the national education curricula puts this study in a national context and provides useful inputs for policy formulation and implementation. However, information on classroom implementation of DRR lessons was obtained from two rural communities in Northern Ghana and therefore the results are location-specific and are not reflective of the entire picture of DRR practice in all parts of the country. This is because, significant differences exist in the education system in terms of the availability of certain resources, such as electricity and computers in urban and rural Ghana, as well as in public and private schools. There is, therefore, a need for more research to identify and analyze such existing differences before generalizations can be made. Additionally, the syllabi content analysis process relied on the use of the 64 identified disaster words. Although, this enabled the study identify the presence of DRR in some of the subjects studied in the upper primary and JHS, as well as analyze their associated teaching, learning, and evaluation techniques, the 64 disaster words are non-exhaustive. The implication is that, this study may have overlooked the presence of certain disaster issues in the syllabi which did not fall within the scope of the 64 identified disaster words. It is also important to note that the presence and frequency of use of the disaster words identified in the syllabi does not necessarily correlate to the importance or time spent on them during classroom lessons.

\section{Results}

\subsection{Comparing and Contrasting Subject Syllabus Contents and Classroom Application of DRR}

\subsubsection{Presence of DRR in Upper Primary and JHS Subjects}

The syllabi content analysis was undertaken to determine the presence of disaster-related words in each of the subjects at the primary and JHS levels. The results are displayed in bubble charts. Figures 1 and 2 show the presence and rate of occurrence (as a percentage) of the analyzed words. The number of bubbles assigned to each subject indicates the number of words present in the syllabus. The rate 
(percentage) of occurrence is represented by the different sizes of the bubbles with the smallest bubble size being $1 \%$ and the largest size being $100 \%$. This was obtained by dividing the frequencies of the word in a disaster-related context, within a particular subject syllabus, by the total number of words contained in that syllabus, multiplied by $100 \%$. The larger the bubble, the more prominently the word is featured in that subject and vice versa.

For instance, danger appears in four subjects in upper primary but among these subjects, it is more prominent in Citizenship Education (66.9\%) followed by the ICT subject (16.9\%), the Ghanaian Language and Culture subject (8.8\%) and the Integrated Science subject (7.4\%). At the JHS, hazard appears only in the Integrated Science and ICT subjects but is very dominant in Integrated Science, with an $83.8 \%$ presence. Climate change forms one of the main drivers of hydrological disasters. However, its mention throughout the entire syllabi content analysis is recorded only in the Integrated Science subject of JHS, and on only one occasion. It therefore has a $100 \%$ rate of occurrence, similar to words such as threat, risk, adapt, pest and parasite, and earth tremor that are present in only one subject.

The results of the primary level syllabi content analysis revealed that, the upper primary syllabi contained 22 of the 64 words used in the search. Out of the nine subjects studied, Mathematics and Physical Education syllabi were the only ones that did not contain any of the words selected for content analysis. Citizenship Education had the highest number of selected words in its syllabus: 17 of the 22 while Creative Arts syllabus contained just one of the words (Figure 1).

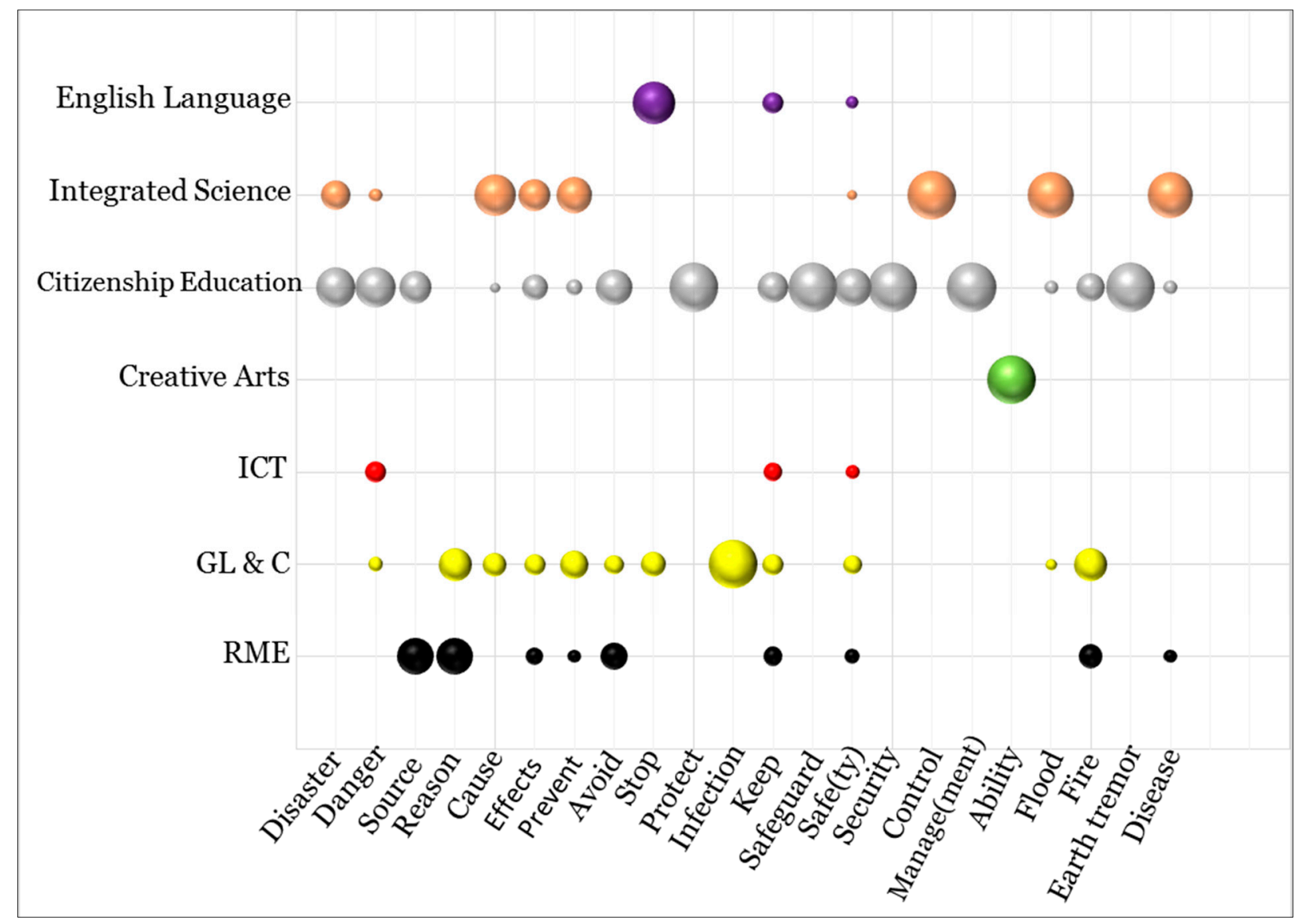

Figure 1. Percentage rate of occurrence of words relating to disasters in the upper primary syllabi (ICT- Information and Communication Technology, GL\&C- Ghanaian Language and Culture, RME- Religious and Moral Education). 
The JHS syllabi analysis showed that eight of the 11 subjects contained 28 of the 64 analyzed disaster words (Figure 2). The JHS Integrated Science syllabus contained 18 of the 28 words, which represents the highest number, while the Music and Dance syllabus had the least number of disaster words; 2 . This indicates a slight increase in both the subject and number of disaster words from that of the upper primary syllabi. For example, disaster words such as hazard, climate change, risk, pest, and parasite, among others, were found in only the JHS syllabi.

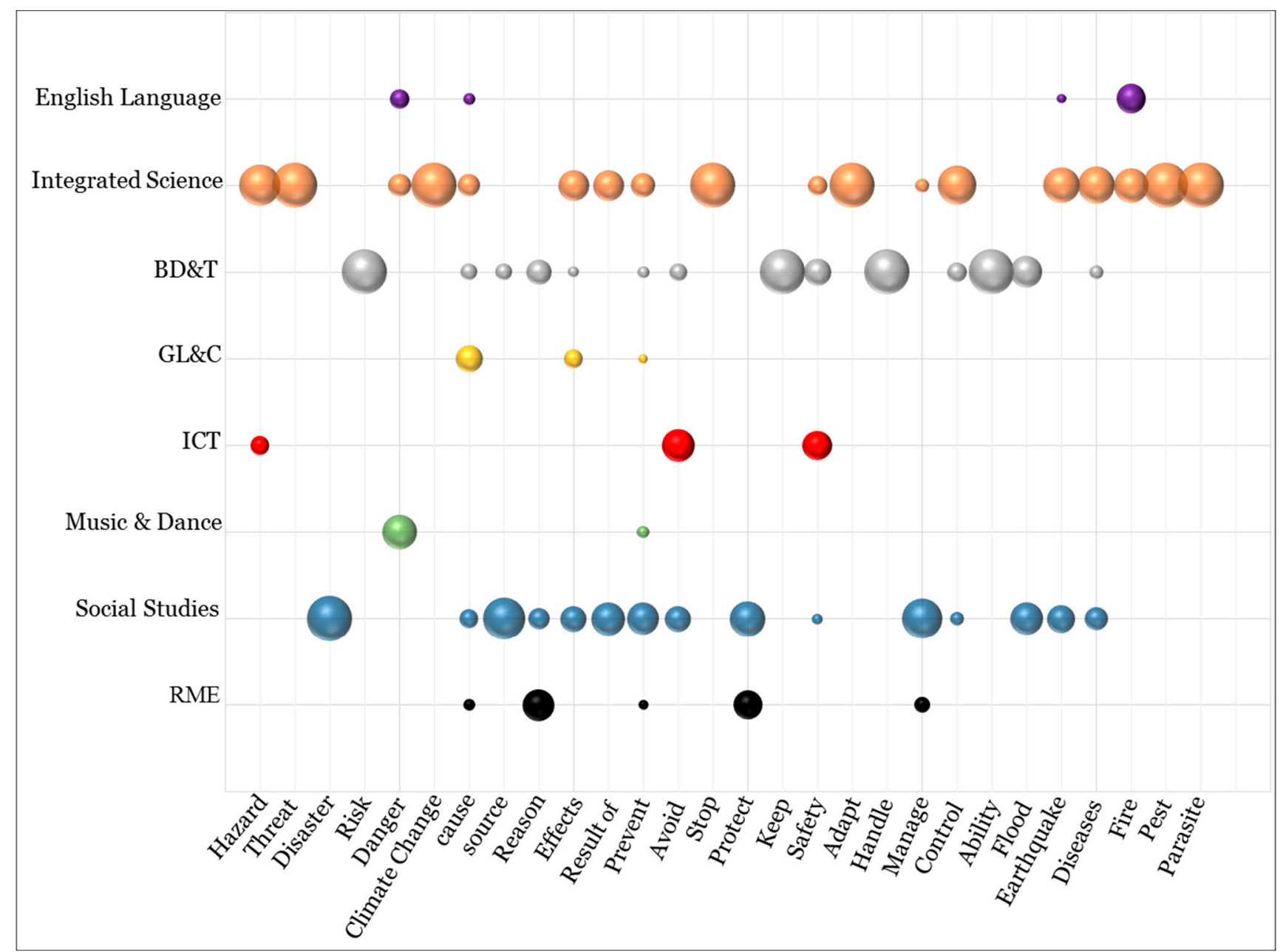

Figure 2. Percentage (rate) of occurrence of words relating to disasters in the JHS syllabi (ICT-Information and Communication Technology, GL\&C-Ghanaian Language and Culture, RME- Religious and Moral Education and BD\&T_-Building Design and Technology).

From the interviews conducted with teachers at upper primary and JHS, all teachers indicated that DRR is present and taught in some selected subjects. When teachers were asked whether the subjects they currently teach contain DRR, an overwhelming majority $(80.0 \%)$ indicated the presence and teaching of DRR topics and themes. The remaining 20.0\% reported not having or teaching DRR related aspects in their current subjects. In all, teachers identified that Natural Science, English, Integrated Science, Mathematics, Social Studies, Citizenship Education, Creative Arts, RME, and Ghanaian Language and Culture contain elements of disaster risk reduction. However, it was realized that BD\&T and Music and Dance were not identified in this list, as opposed to what was observed during the syllabi content analysis. 


\subsubsection{Scope and Content of DRR in Upper Primary and JHS Subjects}

Results from the syllabi content analysis using the latent technique revealed that disaster topics and themes in the upper primary syllabi addressed the following: floods, diseases, conflict, environmental degradation, accidents at home and within the community and fire outbreaks. It is expected that before completing this level, students are aware of what a hazard is, and are knowledgeable about the causes, symptoms, and prevention of selected disasters, such as water-borne diseases, skin diseases, and HIV/AIDS. Environmental degradation and protection of the environment and one's self, as well as disasters such as conflict, floods, fire outbreaks, and earthquakes is expected to have also been addressed. For instance, the ICT subject teaches the safe use of ICT tools and materials in order to prevent events such as fire outbreaks. Three units of the upper primary Ghanaian language subject have also been dedicated to the teaching of "Safety measures" (Table 3, No. 6; Unit 6, page 40 and Unit 7, page 24) and "Environment: degradation and maintenance" (Table 3, No. 6; Unit 8, page 24).

A marginal difference was observed in the types of disaster events addressed in the JHS syllabi when compared to the primary. Similar to the primary syllabi, the JHS syllabi addresses environmental problems such as air pollution, water pollution, land degradation and bush fires, unnatural deaths occurring from conflict, accidents, and disease outbreak. Road safety and safety using various equipment were also addressed. For example, Unit 1 of Section 5 of the JHS Integrated Science subject addresses issues of infectious diseases such as HIV/AIDS, cholera, and cerebrospinal meningitis. Also, Section 1 of the JHS 2 Social Studies subject has been dedicated to teaching environmental issues and Section 2 of the ICT subject for the JHS includes "Health and safety in using ICT tools" (Table 4, No. 6; page 4). However, disaster words in subjects such as English Language and Music and Dance are not strongly emphasized, but have been used as examples to help students develop relevant skills pertaining to the course. An example is in English Language Unit 6 where students are asked to "write letters for publication on topics like causes of bush fires and environmental degradation, among others" (Table 4, No. 5; page 91). Also, in Section 2, unit 2 of the JHS 1 Music and Dance subject, students are required to tell or mime stories based on the dangers of HIV/AIDS, and the difficulties faced by HIV/AIDS patients, to the accompaniment of music (Table 4, No. 3; page 3). The study believes that even in such exercises, knowledge on disasters is transferred to students, representing the need to include these words in the results of the syllabi analysis.

Although responses from teachers did not indicate any clear distinctions between the types of disasters taught in upper primary and those taught in JHS, they indicated floods, droughts, fire, wind storms, pest and disease outbreaks, earthquakes, epidemics such as cholera, conflicts and accidents, as well as environmental degradation and protection, as the commonly addressed themes. Consistent with the responses from teachers, students who were surveyed mentioned that they regularly receive lessons on all of the above themes and topics, as well as landslides. The responses correspond with the disaster words identified in the various subject syllabi, although landslide never appeared. It should be noted however, that landslide was not one of the disaster words selected for assessment in this study. It is plausible that students have been taught or have come across the term landslide during their classroom lessons.

Further analysis of the syllabi revealed that the disaster themes and topics within the upper primary schools are generally limited to addressing causes, effects and prevention, with little attention paid to 
disaster response and recovery. This was indicated by the number of subjects in which the words were captured. From Figure 1, it can be observed that causes, and its synonym words, appears in five different subjects, effects appears in four different subjects and prevent in five different subjects. Response and recovery, and their synonyms, do not appear in any of the upper primary subjects. Although the words manage and control have been used in the upper primary syllabi, their use is limited to the Citizenship Education and Integrated Science subjects, and focuses on cholera, malaria, and environmental degradation. In JHS (Figure 2), causes appears in six subjects, effects appears in four subjects and prevent is in six subjects. The term handle appears in only one subject, while recovery does not appear in any subject. Although the JHS syllabi build on that of the upper primary by including words such as handle and adapt in the BD\&T and Integrated Science subjects, respectively, they are limited to "proper use of tools and how various organisms adjust in different and changing environments". This is inadequate considering the limited scope in which the words have been used to the different disasters captured in the syllabi and experienced in the country. Following similar trends with the scope and content of DRR in the syllabi, results from key informant interview surveys with teachers confirmed that disaster lessons focused predominantly on the types and causes (33.0\%) of disasters and prevention (43.0\%), and less on effective responses to (17.0\%) and recovery from (7.0\%) disasters. Through the focus group discussion, teachers identified felling of trees, burning of bush for hunting purposes, construction of buildings in water ways, chieftaincy disputes and heavy rains and windstorms as some of the causes of disasters. Thus, depending on the type of disaster being considered and circumstances surrounding their occurrence, teachers identify natural (earth tremor, floods etc.), human (floods, drought etc.), political (conflicts, wars etc.) and social (conflicts etc.) causes among others. Responses from the 133 students revealed that types and causes of disasters $(28.0 \%)$ and prevention of disasters $(55.0 \%)$ formed the major part of their disaster lessons while effective response $(9.0 \%)$ and recovery $(8.0 \%)$ formed the least. Consequently, it can be said that teachers and students agreed that students have been equipped with the relevant knowledge to assist with the prevention of disasters identified in the syllabi, but students have limited knowledge and skills to enable them to respond appropriately, manage, and recover from disasters.

\subsubsection{Teaching and Learning Activities for DRR}

All seven identified teaching and learning techniques (see introduction) are captured within the syllabi of the upper primary and JHS and should be used in teaching disaster themes and topics. Based on the upper primary syllabi, teachers are required to teach and engage students with the use of brainstorming and discussion sessions, and invite resource persons (interactive), as well as use videos, posters, pictures, role plays, and dramas (surrogate experiential), experiments and demonstrations (action). They are also expected to undertake field trips to places of relevance to their study (field experiential). Students are also required to source information from the media, such as T.V., radio, and newspapers, on selected issues (inquiry). There is only one instance of referral to the affective technique in the primary 6 Citizen Education syllabus: "pupils to share experience of domestic violence and conflict in the homes" (Table 3, No. 1; page 38). This confirms Selby and Kanagawa's result, which states that the affective learning technique is the least utilized in DRR education [23].

Similarly, the JHS syllabi direct teachers to facilitate discussions and brainstorming (interactive) sessions with students. The syllabi strongly encourage the use of role play (surrogate experiential), 
demonstrations, and experiments (action). The syllabi also require teachers to help students identify, list, name, and tabulate various items relating to disaster events, such as the causative organism, symptoms, mode of spread, prevention, and control of diseases (lecture technique). Table 6 shows the frequency of the use of the various techniques of teaching and learning DRR as directly observed in the syllabi.

Table 6. Presence of the types of teaching and learning techniques in the syllabi.

\begin{tabular}{lcc}
\hline \multirow{2}{*}{ Teaching and Learning Techniques } & \multicolumn{2}{c}{$\begin{array}{c}\text { Frequency of Use of the Various Types of } \\
\text { Teaching and Learning Techniques }\end{array}$} \\
\cline { 2 - 3 } & Upper Primary & Junior High School \\
\hline Interactive (e.g., Brainstorming) & 54 & 60 \\
Surrogate experiential & 5 & 6 \\
Action (experiments, demonstrations) & 5 & 8 \\
Field experiential (fieldtrips) & 11 & 5 \\
Lecture & 4 & 6 \\
Inquiry & 4 & 3 \\
Affective & 1 & 0 \\
\hline
\end{tabular}

Regarding the actual teaching and learning techniques employed in the classroom, an overwhelming majority of teachers $(64.0 \%)$ referred to the lecture technique as the most widely used. The field experiential technique was mentioned by $18.0 \%$, as was the action technique $(18.0 \%)$.

By comparison, a notable difference was observed between the teaching and learning techniques stipulated in the syllabi and those used by teachers in the classroom. While the interactive technique dominated in the syllabi, the lecture technique was most represented in the classroom $(64.0 \%)$. Although the interactive technique was not directly identified by teachers, it is the most dominant in the syllabi. This technique, may however be embedded in all of the above identified techniques, since teaching cannot take place in the absence of interaction and exchanges. It must be noted that exchange or interaction can be a mere affirmation of students understanding of the lesson and this must be distinguished from the interactive techniques. The surrogate experiential, inquiry, affective, and interactive techniques were not identified during key informant interview survey with teachers as methods used in teaching disaster themes and topics but information obtained from group discussion showed that drama (surrogate experiential) is used to enable students to better understand and perceive the DRR lessons taught.

To enable the effective use of various teaching and learning techniques as a way of enhancing lessons on DRR, teachers are expected to undergo in-service skill and competency training organized by recognized stakeholders. Out of the 15 teachers interviewed, $12(73.3 \%)$ said they have not received any form of training on DRR either before or during their careers as teachers. The remaining three (26.7\%) said they had received some form of DRR training during their tertiary education, prior to their teaching career. Results from the interview with the officer from Ghana Education Service (GES), and the focus group discussion with teachers, further revealed that in rare instances when in-service DRR training programs were organized, the majority of teachers are unable to participate due to limited financial, human, and technical resources. Thus, the beneficiaries of such training who are mostly principals, their assistants, and other key stakeholders, are expected to train teachers in the schools. This, however, rarely happens due to time and resource constraints. Facilitation manuals for teachers on DRR are also not 
readily available to aid in the effective delivery of lessons, as indicated by teachers and the officer from GES. The only manual on disaster risk management and reduction distributed during a training workshop organized by United Nations Children Fund (UNICEF) in conjunction with GES in 2010 is available only to participants of the programs who, largely, were not teachers.

Regarding the average length of time spent teaching disaster themes and topics per week, the majority of teachers $(40.0 \%)$ said they dedicate less than $30 \mathrm{~min}$ to DRR related lessons, and $26.7 \%$ said they allocate between $30 \mathrm{~min}$ to one hour. The remaining 33.3\% said they had no idea how much time they spent. The integration of disaster topics and themes into already existing subjects was provided by the 15 teachers interviewed as the main reason for insufficient time spent teaching the topics. The result is confirmed by works done by Selby and Kagawa [23]. This situation has led to less emphasis being placed on disaster issues themselves, which may negatively impact the development of skills and attitudes needed to reduce vulnerability and build resilience to disasters. However, teachers and the officer from GES acknowledged that the current structure of the syllabi and class schedules does not afford for enough space and time to make DRR lessons standalone subjects. According to the officer from GES, this can only be done if the length of time spent by teachers and students in the classroom is extended or certain subjects are excluded from the curricula to make way for a DRR subject. However, previous attempts at withdrawing the RME subject from the syllabi were met with stiff opposition from various stakeholders, thus making it a less feasible option. They therefore recommend that much attention is given to co-curricular activities, which provided a greater opportunity and time for the practical teaching of DRR.

\subsubsection{Evaluation Techniques for DRR Lessons}

Through interviews with the teachers, the following types of evaluation techniques were identified: action oriented, output oriented, knowledge acquisition, recall, and application. These are embedded in homework, class exercises, written exams, and demonstration and practical sessions. The general trend observed from the upper primary and JHS syllabi reveals that the recall technique is the most dominant of all the evaluation techniques. This technique involves assessing students on their ability to remember and reproduce what they have been taught in class. They are asked to list, state, mention, and outline various aspects of disaster lessons. The action-oriented process assesses how active students are in participating in the learning process. Teachers observe the performance of students during these processes and grade them using certain criteria. For example, in the primary 5 Citizenship Education syllabus, students are asked to: "role-play any of the various ways of ensuring safety in their community" (Table 3, No. 1; page 21). Also, in the JHS 1, Religious and Moral Education syllabus, students are required to "undertake environmentally sustaining activities in the school" (Table 4, No. 7; page 2).

The output-oriented assessment involves students producing tangible substances, such as producing environmental management plans, diagrams, models, and posters with messages on disaster topics. Examples include: "Pupils to develop an environmental management plan for the community e.g., recycling paper, collecting plastics" found in the Citizenship Education subject (Table 3, No. 1; page 35, Section 2). In the JHS 3, ICT syllabi, students are required to produce reports and documents on the environment, road safety, and HIV, amongst others. The knowledge acquisition technique assesses students' ability to obtain information from varied sources, such as the Internet, newspapers, television, 
and videos. Students are expected to organize information from these sources and present them in a meaningful form. The application technique requires students to use knowledge they have obtained in the class to solve community problems. However, students are not required to undertake any practical steps to implement the solutions formulated. Examples are found in unit 3 of the class 5 Integrated Science syllabus, where students are asked to: "describe how you will control the spread of cholera in your community" (Table 3, No. 2; page 22).

Teachers identified class exercises (36.0\%), homework (27.0\%), written exams (17.0\%), demonstrations and practical sessions (17.0\%), as well as follow-up (3.0\%), as the main approaches used for evaluating students (Figure 3). As observed from the syllabi, all 15 teachers also stressed that these approaches rely heavily on the recall technique and less on the action-oriented, output-oriented, and application techniques, especially in the primary stages. For instance, during the interview with teachers, a participant noted: "In the primary school, learning outcome is more focused on recall, but at the JHS level, students are expected to apply the knowledge obtained" [43].

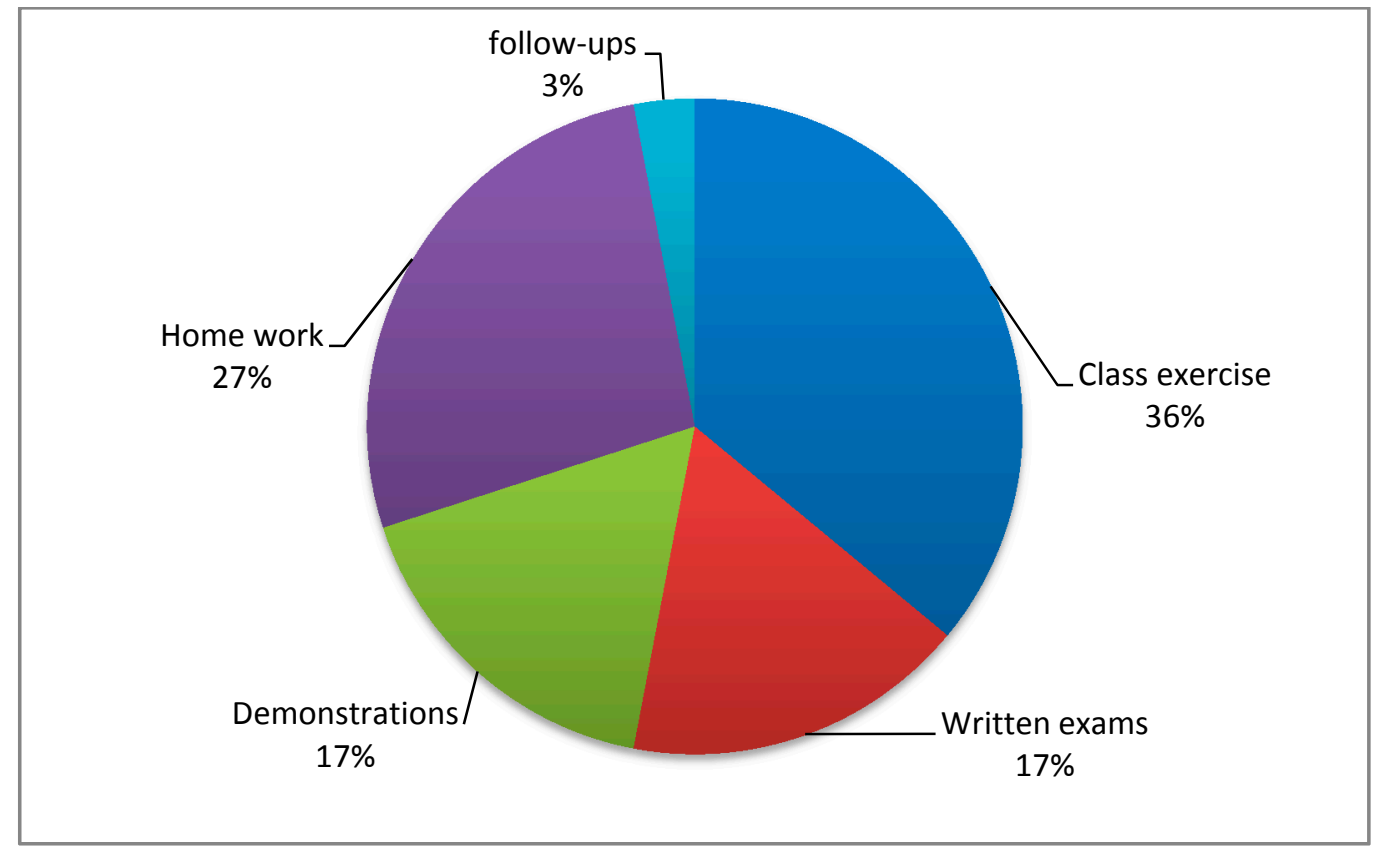

Figure 3. Evaluation approaches used for disaster lessons used for disaster lessons according to interviews with 15 teachers.

\subsection{Skills and Competencies Developed from DRR Education}

In order to assess students' skills and competencies on disaster education, teachers were asked to identify what students could do before, during or after a disaster event. A similar question was posed to students with regards to the practical skills they have acquired from disaster education in the classroom. Responses from students and teachers were assigned to three categories; prevent, respond effectively, and recover. More than one response per category was counted as each respondent could provide answers in more than one category. It was observed from responses of students and teachers that more emphasis is placed on the teaching and learning of skills needed prior to a disaster and less on the skills needed during and after the disaster. Figure 4 shows a comparison of the skills and competencies acquired from classroom disaster education, as outlined by teachers and students. 


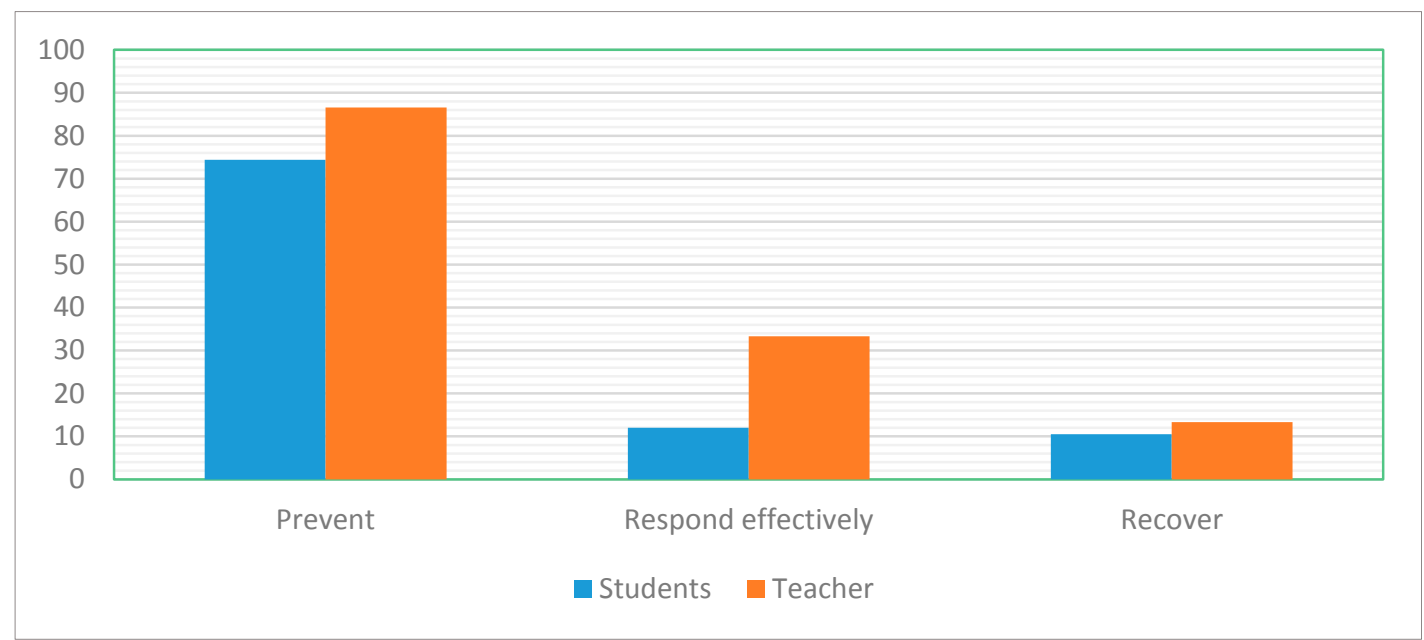

Figure 4. Competencies developed from disaster education (for classification see text).

Approximately $74.0 \%$ of students who said they are taught DRR were confident that, with this knowledge, they could effectively contribute to the prevention of disasters such as floods and fire outbreaks. However, only $12.0 \%$ of these students indicated they would be able to respond effectively, and $10.5 \%$ said they could recover from certain disaster events. The teachers' responses on how applicable they felt their DRR lessons were perceived by students was consistent with what the students themselves said. Overall, the largest proportion of teachers $(86.6 \%)$ said they had instilled adequate preventive knowledge in students, 33.3\% said students have enough responsive knowledge, and (13.3\%) indicated that students could recover properly from certain disaster events. It was further reiterated by teachers during the group discussion that current DRR lesson are directed more towards knowledge acquisition and less on achieving attitudinal changes among students. They acknowledge however that attitudinal changes were difficult to observe and monitor.

\subsection{Challenges Identified}

Disaster risk education is not without challenges, particularly in the knowledge delivery process. Inconsistencies were observed in the DRR education in the syllabi and what goes on in the classroom. Almost all teachers (93.3\%) identified inadequate DRR teaching and learning material as a major hindrance to the delivery of disaster knowledge. They also indicated that the scope and content of disaster education within the syllabi is too narrow, negatively affecting the development of competencies. The GES officer also asserted to this when he mentioned that the scope and depth of the topics should be expanded at both the primary and JHS levels to include contemporary and future hazard, considering adverse human-induced changes occurring in the climatic systems and the environment. He also indicated that DRR education must be extended to the lower primary level which, according to him, has been left out. A lack of student interest and appreciation for lessons taught on unfamiliar disaster events, and insufficient time to teach disaster lessons, were also identified as factors undermining disaster risk education in the study communities.

Furthermore, all schools within the study communities have very limited access to electricity, computers, and the Internet and, as such, online learning tools and materials for disaster risk reduction cannot be utilized. The following are extracts from teachers' notes, outlining the various challenges faced: 
"When teaching, we have pictures of past disasters that we show to the students in order to help them better understand and perceive what is being taught, but there are no lights in most of the schools and thus our inability to make use of the internet and videos to teach students about disasters" [44].

"We sometimes organize practical sessions when teaching, especially when the materials needed to carry out the experiments are available but if they are not, we have to teach them in an abstract way" [45].

"The cost involved in undertaking practical sessions sometimes makes it difficult since some students cannot afford the materials needed for the work" [46].

The officer of GES further indicated that evaluation of the performance of the schools and teachers is greatly hindered by poor road networks as well as the limited human resources (circuit supervisors) that should undertake this evaluation. Each Circuit Supervisor is given between 10 to 15 schools which may be located widely apart to visit and evaluate within a week, making their work tedious and limiting the length of time spent in each school.

\section{Discussion}

DRR education essentially provides a practical and vital means by which vulnerability to disasters can be reduced. National, regional, and global efforts have been initiated to ensure that education continues to be an effective platform for developing a culture of prevention, safety, and resilience among its beneficiaries. In this section, we discuss the implications of the results on developing a culture of prevention, safety, and resilience among students, as well as potential improvements.

\subsection{Curriculum Development to Nurture Relevant Skills and Competencies}

From the analysis conducted, it was determined that the mainstreaming of DRR education has followed an infusionist approach. No subject has been devoted solely to the teaching of DRR at the basic level, although disaster-related themes and topics are included in subjects that already exist. The contents of these subjects, such as Integrated Science, Social Studies, and Citizenship Education, are oriented toward the physical and social environment. Evidence gathered in the content analysis (Figures 1 and 2) and from interviews with teachers, showed that these subjects contain many DRR themes and topics. This typically exemplifies the infusionist approach, which enables DRR topics and themes to be included in existing subjects easily. The infusionist approach, unlike the dedicated subject approach, does not require the development of a new syllabus, teaching and learning materials, or specialized training for teachers. The approach is, therefore, recommended for urgent situations where knowledge of a particular disaster needs to be transferred quickly to avoid dire consequences. For example, in response to the recent Ebola crisis, the Government of Ghana instructed all teachers, irrespective of their areas of expertise, to deliver lessons relating to general knowledge and preventive actions on the virus.

However, the infusionist approach has been criticized for a number of inherent flaws. Selby and Kagawa argue that, the infusionist approach of mainstreaming DRR into the education system usually orients learning outcomes towards knowledge acquisition rather than on the development of skills and attitudes needed for disaster prevention, management, and response [23]. This is simply due to the fact 
that not enough time is dedicated to the practical teaching of DRR issues and may be overlooked during teaching or assessment. Activities such as safety and evacuation drills, community hazard mapping, demonstrations of appropriate disaster response scenarios and disaster simulation games are often not utilized. Even when these practical sessions are undertaken, they are often completed too quickly, and various important aspects are neglected. Also, disaster topics and themes within the subjects are not covered in-depth, and there is no focus on achieving long-term attitudinal changes.

These issues are evident in the education system of the upper primary and JHS in Ghana with particular reference to schools in the study communities. The review of the syllabi revealed that disaster themes and topics are primarily focused on the causes, effects, and prevention of identified disasters, with little or no focus on appropriate responses to, management of, and recovery from the disasters. From the content analysis the study determined that fires, floods, pest and disease outbreaks, earthquakes, and environmental pollution and degradation are the main disasters emphasized in the syllabi. Considering that these are the common forms of disaster in Ghana, students stand a good chance of having knowledge of these disaster forms and are better prepared to prevent, respond to, or recover from them. However, challenges may present themselves if, beyond the basic school, students are not exposed to other disaster events that may occur due to climate and environmental changes. The Hyogo Framework for Action (HFA) monitor indicates that $72 \%$ of countries have included DRR in their curricula, with coverage in primary schools being slightly higher than secondary schools, university or professional institutions [36]. The Intergovernmental Panel on Climate Change (IPCC) and other researches have revealed that climate change will cause the occurrence of unfamiliar disasters in various regions of the world [47-49]. This study therefore recommends that further work should be conducted on reviewing the curriculum of the senior high schools, vocational, and tertiary institutions to ascertain in what way the current education system builds horizontal synergy and advances toward disaster risk reduction education across board.

Teachers from the study communities revealed that not enough time is allocated to the teaching and learning of disaster risk reduction. Disaster drills, disaster stimulations, community hazard mapping, experiments, and demonstrations that lead to the development of relevant skills and attitudes for effective disaster management are not given enough attention due to a lack of teacher training and professional development, along with other resource constraints. Benadusi [16] asserts that, to learn resilience, subjects which contain DRR must be taught using practical and context-oriented activities. Building a culture of prevention, safety, and resilience requires the allocation of sufficient time, not only for the transfer of knowledge and skills but also for reinforcing skills and ensuring attitudinal changes. Without allocating adequate time for the teaching of disaster lessons, teachers in the study communities have realized that students possess the relevant knowledge, but lack the requisite skills needed to effectively respond to and survive a disaster event (Figure 4).

The curriculum review process is expected to help address some of these issues and, in Ghana, it is recommended that a review of the syllabi is undertaken every five years. However, a number of challenges have hindered this process, preventing the timely review of the syllabi. On many occasions, the syllabi review has been done in a fragmented manner. The most recent review, which was to be undertaken in 2010, was postponed by the Government due to financial and logistic limitations. The Government of Ghana later commenced the review with a few selected subjects and, at the time of the interview with the officer from the Ghana Education Service in February 2014, not all subjects had been 
reviewed. The varying dates of publication of the syllabi used for the content analysis confirm this. To a certain extent, this may impact negatively on the current disaster information contained in the syllabi, since seven years is long enough for substantial changes to have taken place in global DRR education.

\subsection{Teachers as Transmitters of Disaster Knowledge}

Apart from the inherent structural and content deficiencies with the infusionist approach, there is also a lack of emphasis on the training and professional development of teachers to effectively handle disaster themes and topics. Teacher training and professional development, also termed "training of trainers," has been identified as a critical element in effective disaster communication and resilience building. Teachers must have not only theoretical knowledge and understanding but also practical skills, competencies, and commitment to teach DRR according to national standards $[19,25,50,51]$. This can only be attained if a conscious effort is made to train teachers before and during their teaching practice.

The low number of teachers $(20.0 \%)$ who have been trained to deliver disaster themes and topics in the study communities brings into question the skills and competencies of the remaining teachers and the effectiveness with which they transfer disaster knowledge. It also reveals weaknesses in the ability of the educational systems to effectively train students, in an increasingly complex and ever-changing society, to actively contribute to reducing their own vulnerability and that of their families and communities. Considering the high level of trust and dependence students, especially those within their formative years, have for their teachers and the information received from them, it is imperative that teachers are well educated and trained to transfer appropriate knowledge and skills.

\subsection{Basic Infrastructure for Effective DRR Education}

This study, acknowledges that laudable achievements have been made in promoting disaster risk education in Ghana by the integration of various aspects into the educational curriculum. However, there is still much work to be done. Darling-Hammond [25] argues that teachers must have access to diverse curriculum resources and technologies, allowing for students to connect and explore ideas, obtain and synthesize information, and solve problems. While the syllabi outlines the combined use of the interactive, surrogate experiential, affective, field experiential, inquiry, action learning, and lecture techniques to deliver disaster lessons (Table 1), the lecture technique is the most dominant during DRR lessons with little focus on the other techniques as shown in the results (Section 3.1.3).

Apart from the lack of teacher training and education, one other major challenge identified was the infrequent use of experience based, interactive and action oriented learning activities. Board games, disaster storybooks, and disaster poems and songs, which are utilized particularly in developing countries where technology is not easily available, are oftentimes not utilized. It is not enough to create awareness of disasters and transfer theoretical knowledge on disaster prevention and response, it is also essential to equip student with the relevant skills and competences. By consolidating the two, students will be able to initiate and or undertake pragmatic efforts at disaster prevention and effective and timely response. Research has shown that innovative and effective curricula worldwide is computer-based [9], but in situations where schools do not have access to a reliable power supply it becomes virtually impossible to make use of this technology in teaching. Virtual learning experiences such as disaster simulations and disaster scenarios, which gives students some practical experience and appreciation of 
unfamiliar disasters as well as build on their thinking abilities, cannot be utilized. The UNISDR [1] states that stimulation games are forms of interactive learning tools which helps in students understanding of DRR. Examples include online disaster simulation games such as "Stop disasters" developed by the UNISDR [1], "Giant bombs" and "Disaster will strike 2" (among many others), cannot be used. It stands to reason, then, that students in Ghana, and especially the Northern Region, may be disadvantaged by their lack of exposure to and experience of innovative and practical techniques needed to enhance their knowledge, skills, and competencies toward disaster prevention, safety, and resilience.

Although Japan, like Ghana, utilizes the infusionist approach, differences are observed in implementation of DRR which could provide useful lessons for Ghana. In Japan, school safety, which includes various aspects of DRR, is split-up into three parts; "general safety of students everyday life", "traffic safety" and "DRR". DRR is combined with disaster management for school infrastructure and school and community support network $[18,52]$. Through safety exercises, and disaster prevention and emergency drills, study visits to disaster museums and centers such as the RSMC Tokyo - Typhoon Center, and the Tsunamic and Earthquake Museum [50,53], among others, students are actively involved in school and community-based risk assessment, risk reduction, and disaster recovery and management activities. The direct involvement of the communities in the activities of the school also ensures that the communities are well equipped to assist the schools in DRR and during disasters. This may help eliminate the "common people expert relationship" that has often existed between DRR institutions and communities [54].

\subsection{Evaluation for Effective DRR Lessons}

According to Angelo and Cross [40], teaching cannot take place in the absence of learning, but when this occurs, it ceases to be teaching and becomes just talking. In order to determine if learning has taken place, students must be evaluated. This helps teachers determine what aspects of the lesson students have learned and how well they have learned it. Effective assessment begins with clear goals as outlined in the general and specific objectives of the syllabi of the educational system in Ghana.

The main driver for the evaluation of disaster lessons within Ghana's basic school system is summative purpose with little focus on formative purpose. The summative purpose is used to determine the knowledge students have acquired, in relation to the outlined learning outcomes. It is used to grade individual student achievement and does not necessarily feed back into the curriculum review process for relevant adjustments to be made. On the other hand, assessment for formative purposes identifies not only what is but also what should be present in knowledge acquisition. This better allows for improvements to be made to the curriculum in a timely and appropriate period $[23,55]$.

Evaluation of students in the study community schools generally takes the summative purpose, since outcomes of the process are not integrated into the needs assessment and curriculum review process to create a feedback loop. Although attempts are made to repeat lessons if the majority of students have not passed the assessment, this is not enough to address the root cause of failures, which may be embedded in either the contents of the syllabi and/or the teaching, learning, and evaluation techniques employed. Whatever the cause, ineffective learning processes can then have significant implications on the outcome of disaster education. The evidence presented in this study is consistent with Selby and Kagawa's [23] assertion that "assessment of student learning is the least considered and least developed element of disaster risk reduction education.” 


\section{Conclusions}

Disaster risk reduction education is of real importance if the survival of current and future generations is to be ensured. However, the nature in which disaster risk reduction is communicated within the educational systems determines, to large extent, its effectiveness in building a culture of prevention, safety, and resilience among students. The study lists important recommendations based on the results of this study, in order to make current disaster education more effective.

This study concludes that education for DRR in Ghana's basic schools enables the development of a culture of prevention, but significantly neglects the development of a culture of safety and resilience among students. In order to address this, first of all the scope and content of the disaster themes and topics needs to be broadened within the upper primary and JHS since the focus is more on transferring knowledge on disaster prevention and less on developing skills and competencies for effective disaster preparedness. This study does not claim the importance of one aspect over the other, but demonstrates that students must be adequately prepared on, not just how to prevent disasters, but also on how to respond to, manage, and recover from disasters. The study therefore suggests that the national government and other stakeholders should jointly perform a thorough curriculum review, with a pilot-based needs assessment, that is representative of the national teaching population. This should also ensure that contemporary and likely disasters are addressed.

Teacher training and professional development are also prerequisites for effective disaster education. The study therefore recommends DRR training as key part of teacher training courses so that teachers garner fundamental knowledge and skills to effectively teach DRR. In addition to this, teachers should undergo regular in-service DRR training so they are kept abreast of new developments and practices in DRR. Creating a culture in schools that supports teachers' continual learning [25] by government, school authorities, and other stakeholders is also recommended. Collaboration is needed, between national and international stakeholders in the education and disaster sectors, to organize training workshops and provide DRR manuals for teachers. Moreover, the training manual on HIV/AIDS and disaster risk management and reduction developed by UNICEF, together with the Ministry of Education, should be made available to teachers across the country. Furthermore, government should develop and distribute supplementary DRR materials, pamphlets and posters for use in schools. Using the study communities in Northern Ghana as a point of reference, we recommend that schools should be resourced with materials and instruments needed to undertake participatory DRR learning techniques stipulated within the syllabi and in DRR literature. Community-school interaction must be strengthened through joint community risk assessment activities and hazard and safety mapping. Board games such as "Riskland", "Let's Get Prepared", and other participatory games, which rely less on technology should be used, considering the current situations pertaining to schools, as a response to the identified discrepancies between the syllabi stipulated and the teaching and learning techniques actually used in the classroom. Long term efforts should be made by the Government of Ghana and other stakeholders at ensuring that schools are equipped with requisite technology to enable students to use disaster simulation, and other innovative and effective media, for learning DRR. Furthermore, a balance between summative and formative purposes of evaluation is recommended for the reinforcement of disaster knowledge, skills, and attitudes, in order to achieve a culture of prevention, safety, and resilience among students. 


\section{Acknowledgments}

This study was conducted as part of the UN-CECAR Africa project: Enhancing Resilience for Climate and Ecosystem Change: An Integrated Approach in Semi-Arid Africa, which was funded by the Japan International Cooperation Agency (JICA) and the Japan Science and Technology Agency (JST). Also, the input from teachers, students, officers from the Ghana Education Service, and other persons who actively contributed to making this study successful, is greatly appreciated. The contributions of the three unknown reviewers of this article are also appreciated.

\section{Author Contributions}

Priscilla Toloo Apronti and Saito Osamu designed the experiment. Priscilla Toloo Apronti carried out the field research, conducted the data analysis, and wrote the first draft of the manuscript. All authors contributed significantly to the preparation of the final manuscript.

\section{Conflicts of Interest}

The authors declare no conflict of interest.

\section{References}

1. UNISDR. Disaster Risk Reduction begins at schools. In World Disaster Reduction Campaign; United Nations International Strategy for Disaster Reduction (UNISDR): Geneva, Switzerland, 2007.

2. Gaillard, J.C. Vulnerability, capacity and resilience: Perspectives for climate and development policy. J. Int. Dev. 2010, 22, 218-232.

3. Kelman, I. Understanding Vulnerability to Understand Disasters; Canadian Risk and Hazards Network: Toronto, ON, Canada, 2011.

4. Brooks, N.; Neil Adger, W.; Mick Kelly, P. The determinants of vulnerability and adaptive capacity at the national level and the implications for adaptation. Glob. Environ. Change 2005, 15, 151-163.

5. Save the Children UK. Legacy of Disasters: The Impact of Climate Change on Children; Save the Children: London, UK, 2007.

6. Tarazona, M.; Gallegos, J. Recent Trends in Disaster Impacts on Child, Welfare and Development 1999-2009; The United Nations Office for Disaster Risk Reduction: London, UK, 2011.

7. Enarson, E.P. Gender and Natural Disasters; Recovery and Reconstruction Department: Geneva, Switzerland, 2000. Available online: http://www.ilo.int/wcmsp5/groups/public/---ed_emp/--emp_ent/---ifp_crisis/documents/publication/wcms_116391.pdf (accessed on 3 March 2014).

8. Mitchell, T.; Haynes, K.; Hall, N.; Choong, W.; Oven, K. The roles of children and youth in communicating disaster risk. Child. Youth Environ. 2008, 18, 254-279.

9. Izadkhah, Y.O.; Hosseini, M. Towards resilient communities in developing countries through education of children for disaster preparedness. Int. J. Emerg. Manag. 2005, 2, 138-148.

10. ESCAP/UNISDR. Reducing Vulnerability and Exposure to Disasters: The Asia-Pacific. Available online: http://www.unisdr.org/we/inform/publications/29288 (accessed on 12 January 2015). 
11. Baez, J.; de la Fuente, A.; Santos, I. Do Natural Disasters Affect Human Capital? An Assessment Based on Existing Empirical Evidence; IZA DP No. 5164; Institute for the Study of Labor: Bonn, Germany, 2010.

12. Bartlett, S. Climate change and urban children: Impacts and implications for adaptation in low-and middle-income countries. Environ. Urban. 2008, 20, 501-519.

13. Morris, K.N.; Edwards, M.T. Disaster risk reduction and vulnerable populations in Jamaica: Protecting children within the comprehensive disaster management framework. Child. Youth Environ. 2008, 18, 389-407.

14. Seballos, F.; Tanner, T.; Tarazona, M.; Gallegos, J. Children and Disasters: Understanding Impact and Enabling Agency; Institute of Development Studies: Brighton, UK, 2011.

15. Petal, M.; Izadkhah, Y.O. Concept note: Formal and informal education for disaster risk reduction. In Proceedings of the International Conference on School Safety, Islamabad, Pakistan, 14-16 May 2008.

16. Benadusi, M. Pedagogies of the unknown: Unpacking "Culture" in disaster risk reduction education. J. Conting. Crisis Manag. 2014, 22, 174-183.

17. Childs, D.; Gordy, M.; Gordon, M. Implementation of the Hyogo Framework for Action, Summary of Reports 2007-2013; United Nations International Strategy for Disaster Reduction (UNISDR): Geneva, Switzerland, 2013.

18. Djalante, R.; Thomalla, F.; Sinapoy, S.M.; Carnegie, M. Building resilience to natural hazards in Indonesia: Progress and challenges in implementing the Hyogo Framework for Action. Nat. Hazards Earth Syst. Sci. 2012, 62, 779-803.

19. Wisner, B. Let Our Children Teach Us: A Review of the Role of Education and Knowledge in Disaster Risk Reduction. Available Online: http://www.unisdr.org/2005/task-force/working\%20groups/ knowledge-education/docs/Let-our-Children-Teach-Us.pdf (accessed on 2 July 2015).

20. Stanganelli, M. A new pattern of risk management: The Hyogo framework for action and Italian practice. Socioecon. Plan. Sci. 2008, 42, 92-111.

21. National Disaster Management Organization. Ghana's Disaster Profile. 2012. Available online: http://www.nadmo.gov.gh/index.php/ghana-s-disaster-profile (accessed on 23 December 2014).

22. Quansah, H.N.B. Ghana Loses $₫ 2.43 \mathrm{~m}$ to Fire in January-February, 2014. Available online: http://graphic.com.gh/business/business-news/21457-ghana-loses-2-43m-to-fire-in-january-february2014.html (accessed on 12 August 2014).

23. Selby, D.; Kagawa, F. Disaster Risk Reduction in School Curricula: Case Studies from Thirty Countries; United Nations Children Fund: New York, NY, USA, 2012.

24. Shaw, R.; Shiwaku, K.; Takeuchi, Y. Disaster Education; Emerald Group Publishing Ltd.: London, UK, 2011.

25. Darling-Hammond, L. Teacher learning that supports student learning. Strength. Teach. Prof. 1998, $55,6-11$.

26. Oteng-Ababio, M. "Prevention is better than cure": Assessing Ghana's preparedness (capacity) for disaster management. Jamba J. Disaster Risk Stud. 2013, 5, 1-11.

27. Ghana Statistical Survey-GLSS 6 2014. Poverty Profile in Ghana 2005-2013. Available online: http://www.statsghana.gov.gh/docfiles/glss6/GLSS6_Poverty\%20Profile\%20in\%20Ghana.pdf (assessed on 13 January 2015). 
28. Songsore, J. Regional Development in Ghana: The Theory and Reality; Woeli Publishing Services: Accra, Ghana, 2011.

29. Avtar, R.; Saito, O.; Singh, G.; Kobayashi, H.; Ali, Y.; Herath, S.; Takeuchi, K. Monitoring responses of terrestrial ecosystem to climate variations using multi temporal remote sensing data in Ghana. In Proceedings of the 2014 IEEE International Geoscience and Remote Sensing Symposium (IGARSS), Quebec City, QC, Canada, 13-18 July 2014.

30. Boafo, Y.A.; Saito, O.; Takeuchi, K. Provisioning ecosystem services in rural savanna landscapes of Northern Ghana: An assessment of supply, utilization, and drivers of change. J. Disaster Res. 2014, 9, 501-515.

31. Boakye-Danquah, J.; Antwi, E.K.; Osamu, S.; Abekoe, M.K. Impact of farm management practices and agricultural land use on soil organic carbon storage potential in the savannah ecological zone of Northern Ghana. J. Disaster Res. 2014, 9, 484-500.

32. Ghana Districts 2006. Northern-tolon. Available online: http:/www.ghanadistricts.com/ districts $/ ? \mathrm{r}=6 \& \_=88 \& \mathrm{sa}=6610$ (accessed on 12 January 2015).

33. Antwi, E.K.; Otsuki, K.; Osamu, S.; Obeng, F.K.; Gyekye, K.A.; Boakye-Danquah, J.; Boafo, Y.A.; Kusakari, Y.; Yiran, G.A.B.; Owusu, A.B.; et al. Developing a community-based resilience assessment model with reference to Northern Ghana. IDRiM J. 2014, 4, 73-92.

34. Ghana Statistical Service. 2010 Population and Housing Census Summary Report of Final Results. Available online: http://www.statsghana.gov.gh/docfiles/2010phc/Census2010_Summary_report_of_ final_results.pdf (assessed on 2 February 2015).

35. Grotberg, E.H. A Guide to Promoting Resilience in Children: Strengthening the Human Spirit; Bernard Van Leer Foundation: The Hague, The Netherlands, 1995.

36. UNISDR. Global Assessment Report on Disaster Risk Reduction. 2015. Available online: http://www.preventionweb.net/english/hyogo/gar/2015/en/gar-pdf/GAR2015_EN.pdf (accessed on 19 March 2015).

37. Mamogale, H.M. Assessing Disaster Preparedness of Learners and Educators in Soshanguve North. Master's Thesis, University of the Free State, Bloemfontein, Free State, South Africa, 2011.

38. The United Nations Children's Fund (UNICEF). Children Charter: An Action Plan for Disaster Risk for Children by Children. 2011. Available online: http:/www.unicef.org/mozambique/ children_charter-May2011.pdf (access on 21 January 2014).

39. Israel, G.D. Determining Sample Size; Institute of Food and Agriculture Sciences, University of Florida Cooperative Extension Service: Gainesville, FL, USA, 2009. Available online: http://www.soc.uoc.gr/socmedia/papageo/metaptyxiakoi/sample_size/samplesize1.pdf (accessed on 23 July 2014).

40. Downe, W.B. Content analysis: Method, applications, and issues. Health Care Women Int. 1992, 13, 313-321.

41. United Nations International Strategy for Disaster Reduction (UNISDR). Terminology. Available online: http://www.unisdr.org/we/inform/terminology (accessed on 22 February 2014).

42. State of Queensland, Department of Community Safety 2010-2013. Disaster Management. Available online: http://www.disaster.qld.gov.au/About_Disaster_Management/Management Phases.html (accessed on 28 November 2014).

43. Alhassan, I. Yoggu D/A Junior High School, Tolon District, Ghana. Personal communication, 2014. 
44. Karim, M. Kpalgun Zion Junior High School, Tolon District, Ghana. Personal communication, 2014.

45. Sulemana, A. Kpalgun Zion Primary School, Tolon District, Ghana. Personal communication, 2014.

46. Abukari, S. Yoggu D/A Junior High School, Tolon District, Ghana. Personal communication, 2014.

47. Houghton, J.T. (Ed.) Climate Change 1995: The Science of Climate Change: Contribution of Working Group I to the Second Assessment Report of the Intergovernmental Panel on Climate Change; Cambridge University Press: Cambridge, UK, 1996.

48. Parry, M.L. (Ed.) Climate Change 2007: Impacts, Adaptation and Vulnerability: Contribution of Working Group II to the Fourth Assessment Report of the Intergovernmental Panel on Climate Change; Cambridge University Press: Cambridge, UK, 2007; Volume 4.

49. Meehl, G.A.; Stocker, T.F.; Collins, W.D.; Friedlingstein, P.; Gaye, A.T.; Gregory, J.M.; Kitoh, A.; Knutti, R.; Murphy, J.M.; Noda, A.; et al. Global climate projections. In Climate Change 2007: The Physical Science Basis. Contribution of Working Group I to the Fourth Assessment Report of the Intergovernmental Panel on Climate Change; Cambridge University Press: Cambridge, UK, 2007.

50. Asia-Pacific Economic Cooperation (APEC). The Role of Education for Natural Disaster. Available online: http://www.criced.tsukuba.ac.jp/math/apec/ICME12/Lesson_Study_set/The_Role_ of_Education_for_Natural_Disasters.pdf (accessed on 13 January 2015).

51. Sensarma, S.R.; Sarkar, A. (Eds.) Disaster Risk Management: Conflict and Cooperation; Concept Publishing Company: New Delhi, India, 2013.

52. Ministry of Education. Acts on Education. 2015. Available online: http://www.moe.gov.gh/ ?moe=Documents\&sect=Acts\%20On\%20Education (accessed on 13 January 2015).

53. Shida, M. Education for disaster prevention in elementary school in Japan. In Proceedings of the EGU General Assembly Conference, Vienna, Austria, 7-12 April 2013.

54. International Federation of Red Cross and Red Crescent Societies. Public Awareness and Public Education for Disaster Risk Reduction: Key Messages. 2012. Available online: http://www.preventionweb.net/files/31061_31061ifrckeymessages2012121.pdf (accessed on 11 May 2015).

55. Angelo, T.A.; Cross, K.P. Classroom Assessment Techniques. 1993. Available online: http://sloat.essex.edu/sloat/delete/contentforthewebsite/classroom_assessment_techniques.pdf (accessed on 2 January 2015).

(C) 2015 by the authors; licensee MDPI, Basel, Switzerland. This article is an open access article distributed under the terms and conditions of the Creative Commons Attribution license (http://creativecommons.org/licenses/by/4.0/). 